\title{
Contributions of Land Utilization Differences and Changes in Zhongyuan Urban Agglomeration to Regional Thermal Environment
}

\author{
Qingkong Cai*, Erjun Li**†, Yafei Zhang***, Guo Wang* and Chao Chen* \\ *College of Civil Engineering, Henan University of Engineering, Zhengzhou, Henan 451191, China \\ **College of Human and Social Sciences, Henan University of Engineering, Zhengzhou, Henan 451191, China \\ ***College of Geological Engineering and Geomatics, Chang' an University, Xi'an, Shanxi 710054, China \\ †Corresponding author: Erjun Li; hnwxlej@163.com
}

Nat. Env. \& Poll. Tech.

Website: www.neptjournal.com

Received: 12-04-2021

Revised: 20-08-2021

Accepted: 28-08-2021

Key Words:

Contribution index

Land utilization

Urban agglomeration

Urban thermal environment

\begin{abstract}
Accelerated urbanization has given rise to sharp environmental changes in urban underlying surfaces, thus changing the regional thermal environment and endangering the ecosystem balance. The thermal environment is complex, and the influence laws of land utilization differences and changes in the thermal environment in different seasons and under different daytime and nighttime conditions are unclear. In this regard, effective measures should be implemented to reduce the regional thermal environmental effect and determine the influence laws of land utilization differences and changes in the regional thermal environment. Zhongyuan urban agglomeration was applied as the study area. Two-year MODIS eight-day synthesized surface temperature product and land utilization monitoring data were obtained by remote sensing and used to analyze the influencing characteristics of different cities and land utilization types on the thermal environment of urban agglomeration from the angles of interannual differences and seasonal differences. During 2010-2018, the area changes in different land utilization types in the study area are significant with decreasing farmland area and increasing forest land and construction land. The farmland and forest land have the most significant influences on the regional thermal environment, where the farmland exerts a warming effect on the regional thermal environment and the forest land exerts a cooling effect. In different seasons and under different daytime and nighttime conditions, the construction land shows a strong warming effect on the regional thermal environment. The contribution indices of Changzhi city and Jincheng city to the thermal environment of the urban agglomeration are negative, so they exert the cooling effect. The warming or cooling role played by Handan city, Liaocheng city, and Xingtai city in the thermal environment is transited under different daytime and nighttime conditions, namely, they exert the warming effect in the daytime and the cooling effect in the nighttime. The seasonal differences in the contributions of different cities to the regional thermal environment are the most apparent in summer and winter. The contribution indices are generally high in summer and winter and low in spring and autumn. Conclusions have theoretical significance for scientifically regulating the regional thermal environment.
\end{abstract}

\section{INTRODUCTION}

Rapid urbanization has resulted in drastic environmental changes in the urban underlying surface, and one of the most obvious negative effects is the rise of urban surface temperature. Land utilization/coverage change (LUCC), which is the most direct pattern of manifestation of the interaction between human activity and the natural environment, plays a significant role in the regional thermal environment (Liu et al. 2014). Urban heat island (UHI) is a concentrated reflection of urban thermal environmental characteristics (Memon et al. 2008). Since the concept of "heat island" was proposed by Howard at the beginning of the 19th century, scholars have carried out a large quantity of research work regarding the monitoring and recognition (Dai et al. 2009, Zhou et al. 2008), evaluation and diagnosis (Oke et al. 1987, Zhang et al. 2012), simulation and regulation (Meng et al. 2010, Yue et al. 2010), etc. of UHI. With the rapid outward urban expansion and continuous population aggregation toward the cities, the thermal environment of urban agglomeration is faced with unprecedented challenges under the impact of global warming (Chi et al. 2015).

Scholars have explored eco-environmental problems triggered by changes in the urban thermal environment during urbanization in recent years. When studying the relationship between surface temperature and landscape patterns, Zhou et al. pointed out the importance of seasonal aspect changes (Zhou et al. 2014). Carlson et al. put forward a method for extracting impervious surface by using the vegetation coverage; however, the vegetation coverage was affected by seasonal changes, which generated a certain influence on studies with respect to impervious surface and surface temperature (Carlson 
et al. 2000). Taking Houston in America for example, Streuker discussed the relationships of the spatial distribution of urban heat island with the urban heat island intensity and suburb temperature (Streutker 2002). Rigo et al. analyzed differences in urban surface temperatures measured by different satellites from those obtained through field measurement; the difference value between the surface temperature provided by MODIS and the measured surface temperature was smaller than 5\% (Rigo et al. 2006). The urban thermal environment has been frequently investigated also in China. Tang et al. used three-period Landsat ETM+ image data to discuss the relationships of the surface temperature in Changchun city in summer with the coverage of impervious surface and vegetation coverage (Tang et al. 2017). Taking the mountainous city Chongqing for example and considering altitude, slope, aspect, surrounding landform, etc., Jia found that the surface temperature with an altitude of above $1,000 \mathrm{~m}$ presented an obvious linear relation to the altitude (Jia 2014). Han et al. used the MODIS surface temperature product to discuss the influences of spatial-temporal changes in the thermal environmental safety pattern in Yangtze River Delta urban agglomeration and the changes in the land utilization; the results showed that the excessively high proportion of construction land and excessively low proportion of forest land were the primary causes for the declining safety level of the thermal environment (Han et al. 2017). Xie et al. analyzed the spatial-temporal change laws of the urban thermal environment in the Nanchang City area during 1996-2016 and displayed the relationships of the urban thermal environment with land utilization and manmade heat discharge (Xie et al. 2019). Qiao et al. analyzed the spatial-temporal pattern of urban thermal environmental risks and their characteristics in Beijing city; the results indicated that the urban thermal environmental risks presented a rising trend in Beijing, where the proportion of extremely high-risk areas was elevated from $9.66 \%$ to $12.08 \%$ (Qiao et al. 2019). Wang et al. analyzed the relationships of urban land utilization type and pattern features with the surface thermal environment and stated that the surface temperature varied considerably with land utilization types; among which, the surface temperatures of industrial land, land for roads and squares, and residential land were higher than those of river, garden, and forest land (Wang et al. 2013).

To sum up, eco-environmental problems induced by changes in the thermal environment during the urbanization progress have been analyzed in detail; however, considering the complexity of the urban thermal environment, few studies have involved interannual and seasonal differences in the influences of land utilization types on the urban thermal environment. In addition, most studies used a single city as the study object, few works were conducted at the scale of urban agglomeration. The thermal environmental problem triggered by the rapid urbanization stands out in Zhongyuan urban agglomeration, which is one of 19 national-level urban agglomerations in China. Based on the above analysis, Zhongyuan urban agglomeration was taken as the study area, and the influence mechanism and action laws of different cities and different land utilization types on the thermal environment in this urban agglomeration were analyzed from the respective angles of interannual differences and seasonal differences to reasonably utilize land resources, optimize urban construction planning, relieve and control urban high temperature, and provide a theoretical and practical basis for constructing a beautiful Zhongyuan region.

\section{MATERIALS AND METHODS}

\section{Profile of the Study Area}

Zhongyuan urban agglomeration is Central Plains (centering on Henan Province) located in Central and East China and the junction between the coastal open region and central and western regions in China. It is one of the core regions with enormous vigor and potential in the future economic development pattern of China and has an important node for forging a new growth pole of China's economic development. The geographical location is between east longitude of $110^{\circ} 15^{\prime}-118^{\circ} 10^{\prime} \mathrm{E}$ and northern latitude of $30^{\circ} 23^{\prime}-37^{\circ} 47^{\prime} \mathrm{N}$. According to the Development Plan of Zhongyuan urban agglomeration approved by the State Council on December 28, 2016, Zhongyuan urban agglomeration has jurisdiction over 30 cities in five provinces: Henan, Shanxi, Hebei, Shandong, and Anhui (Fig. 1). The land area of the administrative region is $287,000 \mathrm{~km}^{2}$, accounting for $3.0 \%$ of the total land area of the nationwide administrative region. The main regional landform is plain, along with low hills and mountains. It belongs to temperate monsoon climate and subtropical monsoon climate, with four distinctive seasons (high temperature and rainy summer and cold and dry winter). By the end of 2017 , the urban built-up area in Zhongyuan urban agglomeration is $7,400 \mathrm{~km}^{2}$, accounting for $12.0 \%$ of the total national urban built-up area; the total population was $188,881,400$ at the end of the year, accounting for $13.6 \%$ of the total national population. The city size in Zhongyuan urban agglomeration has been continuously expanded, the population absorption ability continuously strengthened, and the cohesion and overall competitiveness continuously enhanced. Promoting the development of Zhongyuan urban agglomeration will be of great strategic importance for accelerating and facilitating the rising of Central China, thereby boosting the new-type urbanization and expanding the new space for China's economic development. 


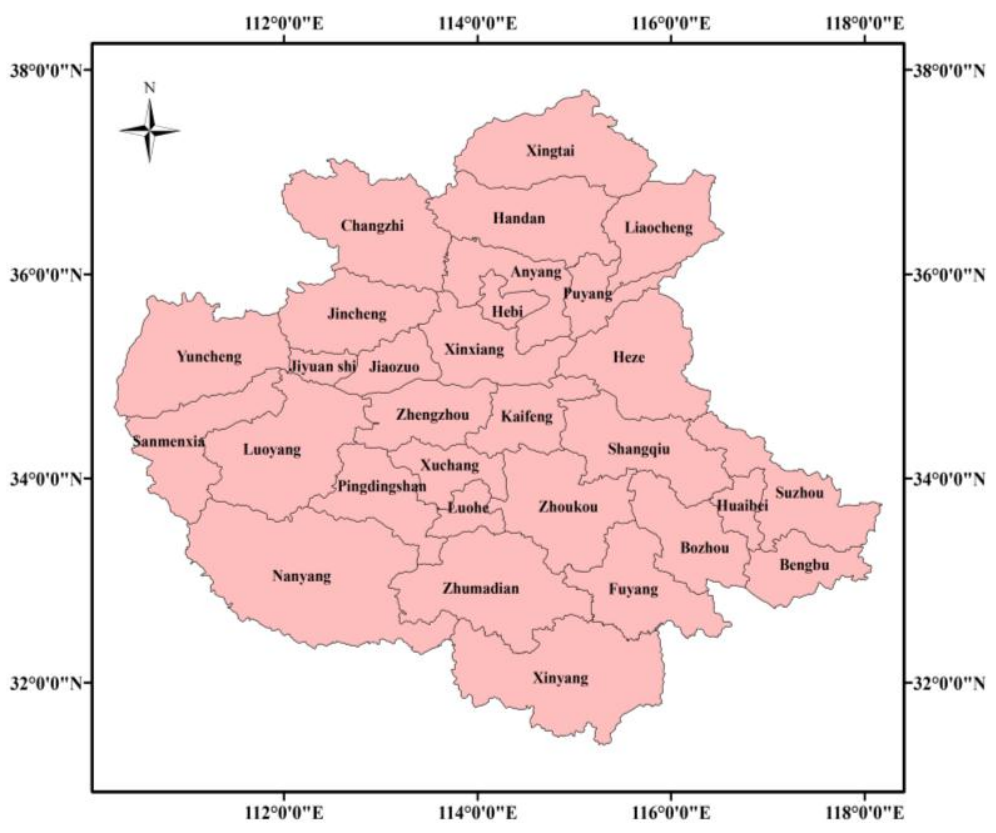

Fig. 1: Geographical location of the study area.

\section{Data Collection and Preprocessing}

The data sources used in this study mainly included MODIS surface temperature data and land utilization data, where the surface temperature data derived from the MODIS eight-day synthesized surface temperature product (MOD11A2) provided by the National Aeronautics and Space Administration (NASA) of the United States of America, the spatial resolution of images was $1000 \mathrm{~m}$ and the column numbers were h26v05 and h27v05. The year-round data in two periods, namely, 2010 and 2018, were downloaded. The original data were acquired by Aqua Satellite when passing the territory at 13:30 and 01:30 to characterize the surface reflection conditions in the surface warming and cooling time periods (Qiao et al. 2014, Sun et al. 2018, Peng et al. 2014). The surface temperature data product was acquired through the inversion using the split-window algorithm, with the precision reaching as high as $1 \mathrm{~K}$ (Wan et al. 2004). The preprocessing work mainly included image reprojection, image synthesis, image splicing, and image clipping. The images were re-projected using the MODIS reprojection tool (MRT), the temperature product was then synthesized into the monthly average surface temperature data through the maximum value composite method, and the monthly average surface temperature data were finally obtained through image splicing and image clipping. The synthesized surface temperature data of the study area in June are presented in Fig. 2.

The land utilization data originated from 1:100000 China land utilization remote sensing monitoring datasets in 2010 and 2018 provided by the Resource and Environment Science and Data Center, Chinese Academy of Sciences. The land utilization types included six level I types (Farmland, forest land, grassland, water area, residential land and unused land) and 25 level II types, all of which have been widely applied to various fields, such as spatial-temporal pattern analysis of the urban thermal environment and comprehensive eco-environmental evaluation (Liu et al. 2004). In this study, the urban and rural land, industrial and mining land, and residential land were called by a joint name, that is, construction land and the two-period land use classification maps (Fig. 3) were obtained through image splicing and image clipping.

\section{Methodology}

Acquisition of surface temperature data: The MODIS eight-day synthesized surface temperature product only recorded the surface thermal radiation values under cloudless conditions; as such, the surface thermal radiation value should be transformed into surface temperatures. Based on the data header files, the radiation scaling ratio of the MODIS temperature product was obtained as 0.02 , and radiation scaling intercept was set as 0 , so the conversion formula for surface temperature is:

$$
T=0.02 \cdot D N-273.15
$$

where $T$ is the surface temperature (unit, ${ }^{\circ} \mathrm{C}$ ), and $D N$ is the brightness value of the image element.

The seasonal differences in the contributions of different land utilization types to the thermal environment in urban 


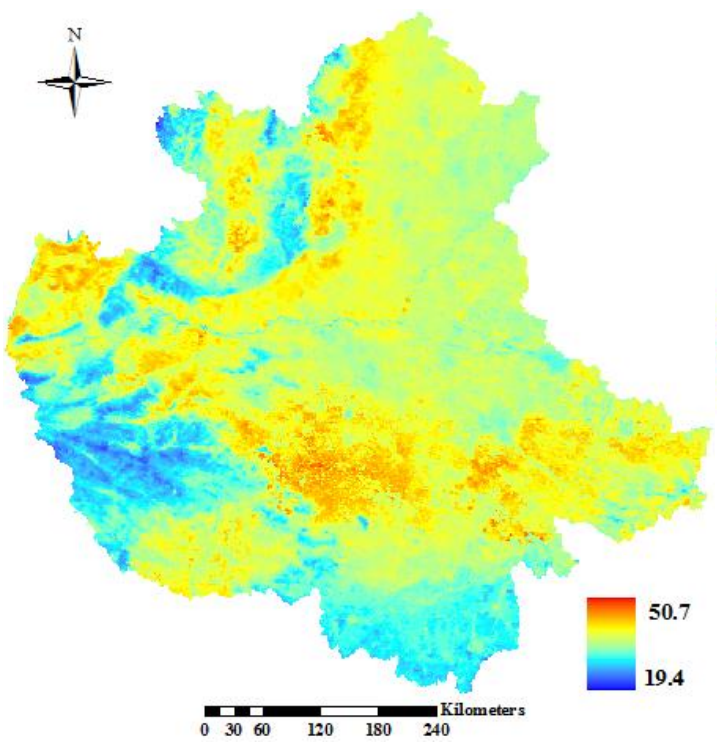

(a) June 2010

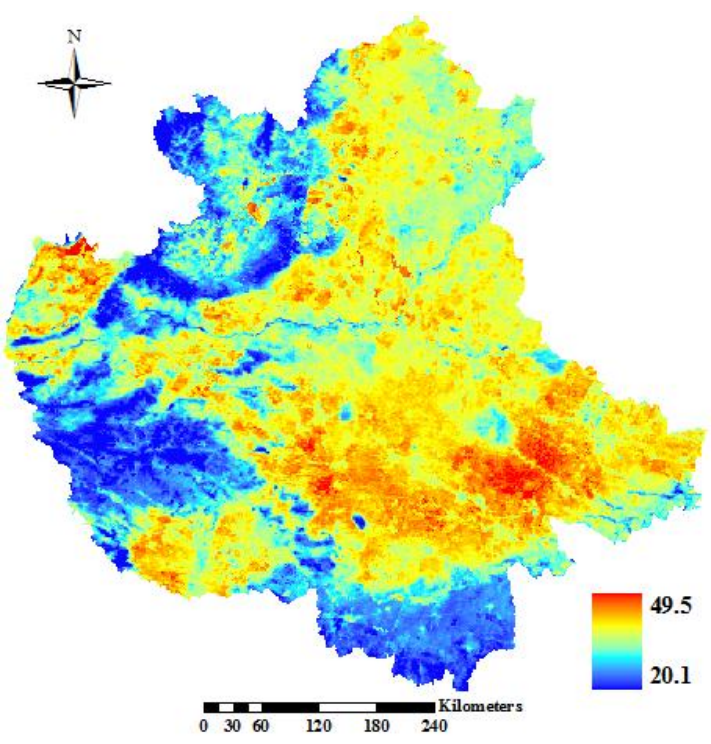

(b) June 2018

Fig. 2: Surface temperature graphs in Zhongyuan urban agglomeration in June 2010 and 2018.

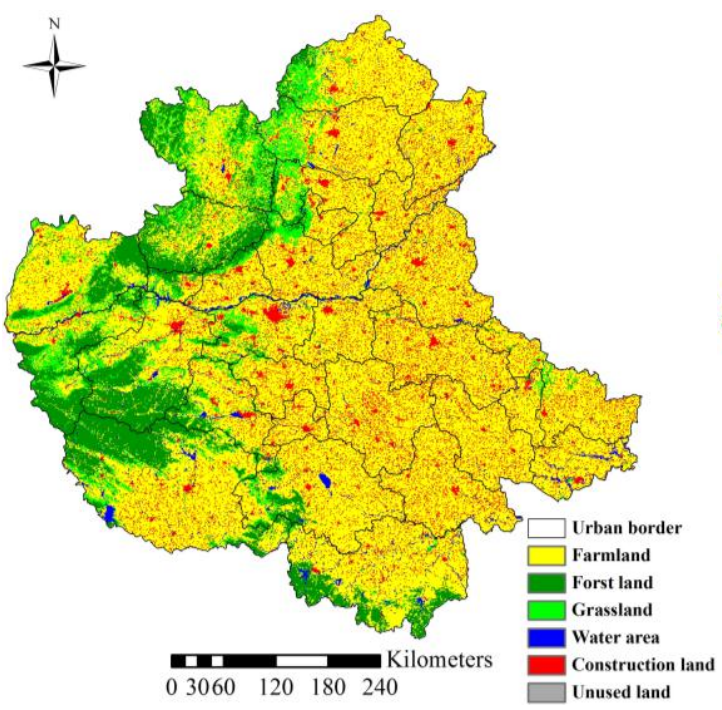

(a) 2010

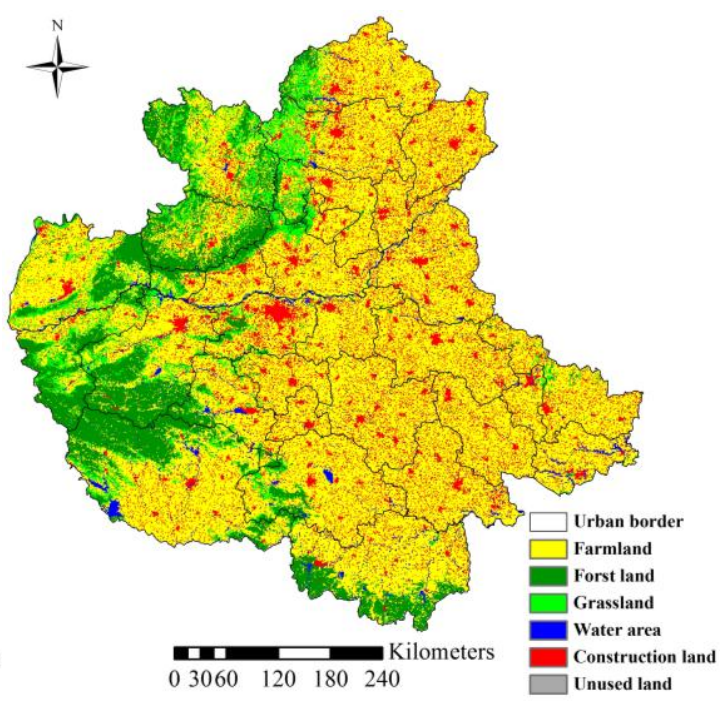

(b) 2018

Fig. 3: Land utilization classification maps of Zhongyuan urban agglomeration in 2010 and 2018.

agglomeration were compared. The synthesized MODIS monthly average temperature data were used to calculate the seasonal average and daily (daytime and nighttime) average surface temperatures in spring (March-May), summer (June-August), autumn (September-November), and winter (December-February in the next year).
Calculation of contribution index: The influence mechanism of different cities on the regional thermal environment differed to some extent due to the spatial heterogeneity of land utilization types. The contribution index (CI) was used to quantitatively characterize the contributions of land utilization types to the urban thermal environment. CI is the 
product of the difference value between the average surface temperature of one land utilization type and regional average surface temperature with the proportion of the area of this land utilization type in the total regional area (Xu 2009, Qiao et al. 2013). CI is calculated by the following formula:

$$
C I=D_{t} \times S
$$

Where $C I$ is the CI of one land utilization type to the thermal environment; $D_{t}$ is the difference value between the average surface temperature of one land utilization type and regional average surface temperature, and $S$ is the proportion occupied by one land utilization type in the total regional area. The positive or negative CI represents the warming or cooling effect of land utilization type on the urban thermal environment, and its value denotes the contribution of this land utilization type to the urban thermal environment. In a similar way, the CI of each city to the regional thermal environment is the product of the difference value between average surface temperature and regional average surface temperature with the proportion occupied by the city area in the total regional area (Sun et al. 2018).

\section{RESULTS AND DISCUSSION}

Differences in the Contributions of Different Land Utilization Types to the Thermal Environment of the Urban Agglomeration

Interannual differences: The area proportion of each land utilization type in the two periods was calculated based on the land utilization data in 2010 and 2018. By using the vector data and surface temperature data of land utilization types, the daytime average surface temperatures in 2010 and 2018 were respectively extracted to obtain the CI value of each land utilization type to the thermal environment (Table 1).

As given in Table 1, among different land utilization types, the proportion of farmland was the largest in the total study area, followed by forest land, construction land, grassland, water area, and unused land. From 2010 to 2018, the area proportion of farmland in the study area was reduced from $66.43 \%$ to $63.70 \%$, while the areas of forest land, water area, and construction land were increased. The surface temperatures of farmland and construction land were higher than the regional average surface temperature, and their CI values were increased from 0.31 and 0.06 in 2010 to 0.43 and 0.12 in 2018, respectively; the warming effect on the regional thermal environment was obviously enhanced. The surface temperatures of forest land, grassland, water area, and unused land were all lower than the regional average surface temperature, indicating that they exerted a cooling effect on the regional thermal environment, where the CI value of forest land was transformed from -0.31 in 2010 to -0.41 in 2018, and the cooling effect was enhanced somehow. The temperature anomaly value of grassland was transformed from -0.29 in 2010 to -0.89 in 2018 , and the CI values of water area and unused land were negative, manifesting their cooling effect on the regional thermal environment.

Seasonal differences: Based on the vector data of each land utilization type and MODIS temperature product data, the average temperatures of each land utilization type in the daytime and nighttime in 2010 and 2018 were extracted by four seasons, respectively. The seasonal CI value of each land utilization type to the thermal environment was obtained (Table 2). The broken line graphs of seasonal CI of each land utilization type to the thermal environment of Zhongyuan urban agglomeration in 2010 and 2018 were drawn (Fig. 4).

As given in Table 2 and Fig. 4, the CI value of farmland presented significant daytime and nighttime differences. The daytime warming effect was more obvious than the nighttime warming effect, which was mainly ascribed to the solar radiation and seasonal characteristics of crops. Except that the CI values of farmland in the daytime of spring and nighttime of winter were smaller than 0 , the CI values in other seasons were all greater than 0 , with a significant warming effect. The cooling effect of forest land was the most remarkable in sum-

Table 1: CI values of land utilization types to thermal environment of Zhongyuan urban agglomeration in 2010 and 2018.

\begin{tabular}{lllllll}
\hline \multirow{2}{*}{ Land-use type } & \multicolumn{2}{c}{2010} & & \multicolumn{2}{c}{2018} \\
\cline { 2 - 7 } & Area ratio & Temperature anomaly & CI & Area ratio & Temperature anomaly & CI \\
\hline Farmland & $66.43 \%$ & 0.46 & 0.31 & $63.70 \%$ & 0.68 & 0.43 \\
Forest land & $13.85 \%$ & -2.27 & -0.31 & $14.04 \%$ & -2.92 & -0.41 \\
Grassland & $6.47 \%$ & -0.29 & -0.02 & $6.11 \%$ & -0.89 & -0.05 \\
Water area & $2.05 \%$ & -0.78 & -0.02 & $2.20 \%$ & -0.74 & -0.02 \\
Construction land & $11.13 \%$ & 0.54 & 0.06 & $13.91 \%$ & 0.87 & 0.12 \\
Unused land & $0.07 \%$ & -0.69 & -0.00 & $0.04 \%$ & -0.10 & -0.00 \\
\hline
\end{tabular}


Table 2: CI values of land utilization types to the thermal environment of Zhongyuan urban agglomeration in 2010 and 2018.

\begin{tabular}{|c|c|c|c|c|c|c|c|c|c|}
\hline \multicolumn{2}{|c|}{ Land-use type } & \multicolumn{4}{|c|}{ Contribution index in 2010} & \multicolumn{4}{|c|}{ Contribution index in 2018} \\
\hline & & Spring & Summer & Autumn & Winter & Spring & Summer & Autumn & Winter \\
\hline \multirow[t]{6}{*}{ Day } & Farmland & -0.06 & 0.50 & 0.61 & 0.16 & 0.21 & 0.56 & 0.74 & 0.21 \\
\hline & Forest land & -0.02 & -0.56 & -0.56 & -0.12 & -0.31 & -0.65 & -0.68 & -0.00 \\
\hline & Grassland & 0.16 & -0.04 & -0.18 & -0.02 & 0.03 & -0.10 & -0.18 & 0.03 \\
\hline & Water area & -0.02 & -0.02 & -0.02 & -0.00 & -0.03 & -0.03 & -0.02 & -0.00 \\
\hline & Construction land & -0.06 & 0.14 & 0.15 & 0.00 & 0.11 & 0.22 & 0.15 & 0.01 \\
\hline & Unused land & -0.00 & -0.00 & 0.00 & -0.00 & -0.00 & 0.00 & -0.00 & -0.00 \\
\hline \multirow[t]{6}{*}{ Night } & Farmland & 0.06 & 0.28 & 0.05 & -0.15 & 0.03 & 0.27 & 0.05 & 0.46 \\
\hline & Forest land & -0.04 & -0.32 & -0.06 & 0.14 & -0.09 & -0.33 & -0.08 & 0.21 \\
\hline & Grassland & -0.04 & -0.07 & 0.23 & -0.04 & -0.04 & -0.08 & -0.03 & 0.05 \\
\hline & Water area & 0.03 & 0.02 & 0.03 & 0.02 & 0.02 & 0.02 & -0.04 & 0.07 \\
\hline & Construction land & 0.04 & 0.09 & 0.04 & 0.01 & 0.07 & 0.13 & 0.06 & 0.28 \\
\hline & Unused land & 0.00 & 0.00 & -0.00 & -0.00 & 0.00 & 0.00 & 0.00 & 0.00 \\
\hline
\end{tabular}

mer and autumn, and the CI values were increased from -0.56 and -0.56 in 2010 to -0.65 and -0.68 in 2018 , respectively; the cooling effect on the regional thermal environment was enhanced. The CI values of grassland in the daytime of spring and nighttime of autumn were greatly different, exerting a certain cooling effect on the regional surface temperature. In different seasons and under different daytime and nighttime conditions, the construction land showed a strong warming effect on the regional thermal environment. The daytime and nighttime differences in the CI value of water area to the thermal environment were significant; the $\mathrm{CI}$ value was negative in the daytime (cooling effect) and it was positive in the nighttime (warming effect). The CI value of unused land to the thermal environment of this urban agglomeration was approximately 0 mainly because the unused land accounted for a small proportion in the regional area. Therefore, the unused land contributed little to the thermal environment.
Differences in CI Values of Different Cities to the Thermal Environment of Zhongyuan Urban Agglomeration

Interannual differences: The 30 cities in the study area were taken as the statistical units, and their vector data and MODIS temperature data were used to calculate the CI values of each city to the urban thermal environment under different daytime and nighttime conditions in 2010 and 2018. The statistical results were plotted into a histogram (Fig. 5).

As shown in Fig. 5, the CI values of Changzhi city and Jincheng city to the study area in different years and different daytime and nighttime conditions were all negative, so they exerted a cooling effect on the thermal environment of this urban agglomeration in the daytime and nighttime, where the cooling effect of Changzhi city was the most significant. The CI value in the daytime was transformed from - 0.04 in 2010 to -0.08 in 2018 , and that in the nighttime from -0.21 in 2010 to -0.18 in 2018 . The CI values of Xingtai city, Handan city,

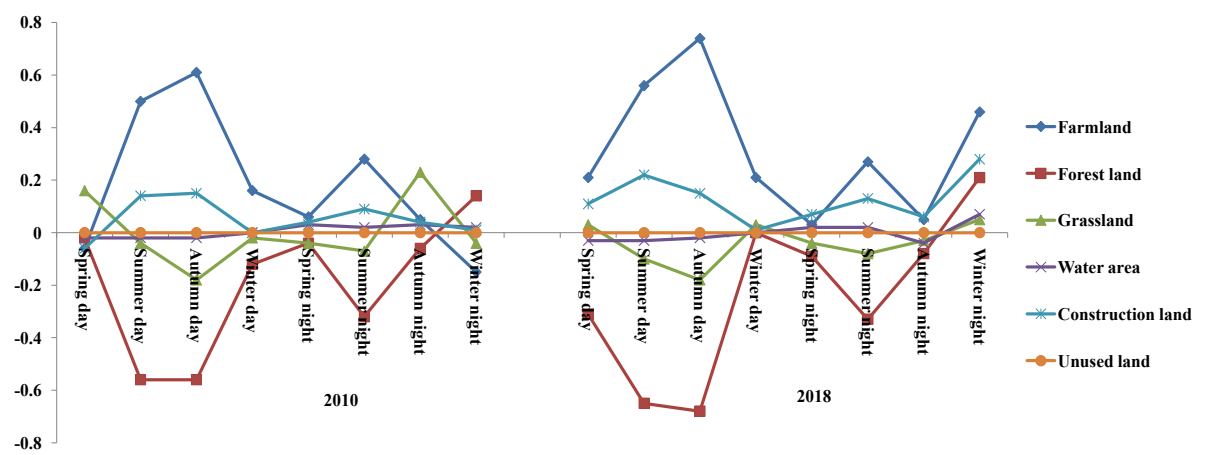

Fig. 4: Seasonal CI values of land utilization types to the thermal environment of Zhongyuan urban agglomeration in 2010 and 2018. 
and Liaocheng city were greater than 0 in the daytime and smaller than 0 in the nighttime, so they exerted a warming effect in the daytime and cooling effect in the nighttime. In the diurnal changes, the warming and cooling roles of the urban thermal environment were transited, namely, the warming effect was exerted in the daytime and the cooling effect in the nighttime. The CI values of other cities were positive, indicating that the average temperatures in these cities were always higher than the average temperature in the urban agglomeration, they generated a warming effect in daytime and nighttime, among which Nanyang city was the most typical; this city generated a warming effect on the regional thermal environment.
Seasonal differences: The CI values of each city to the thermal environment of Zhongyuan urban agglomeration under different daytime and nighttime conditions were statistically analyzed based on the MODIS temperature data and vector data of each city in 2018 (Table 3 and Fig. 6).

Table 3 and Fig. 6 show that different cities presented seasonal differences in the CI value to the thermal environment of this urban agglomeration. To be more specific, the CI value was greater than 0 in spring and summer, and it might be positive or negative in autumn and winter. The seasonal differences in the CI value to the thermal environment were the most obvious in summer and winter, and the CI values in spring and autumn fluctuated around 0 , where Pingdingshan

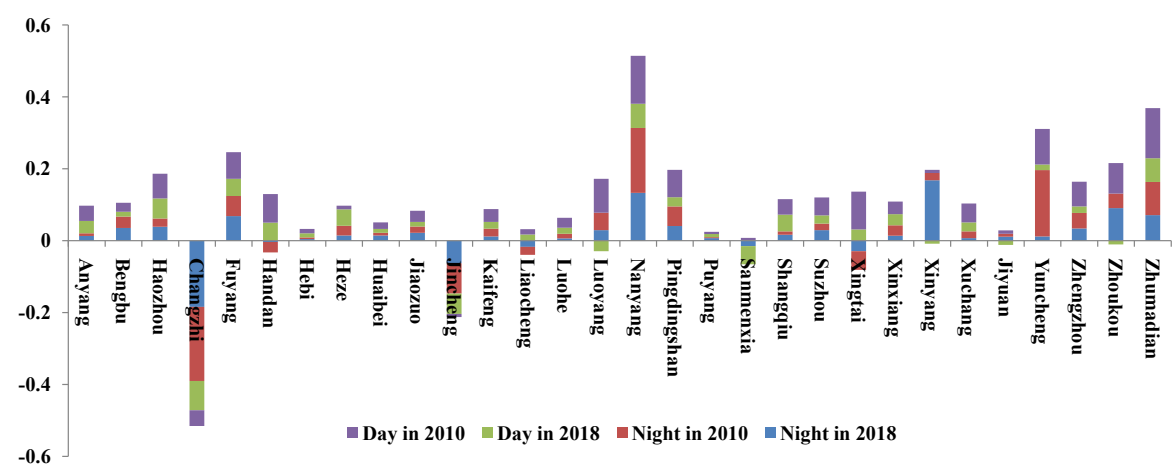

Fig. 5: CI values of different cities to the thermal environment of Zhongyuan urban agglomeration in 2010 and 2018.

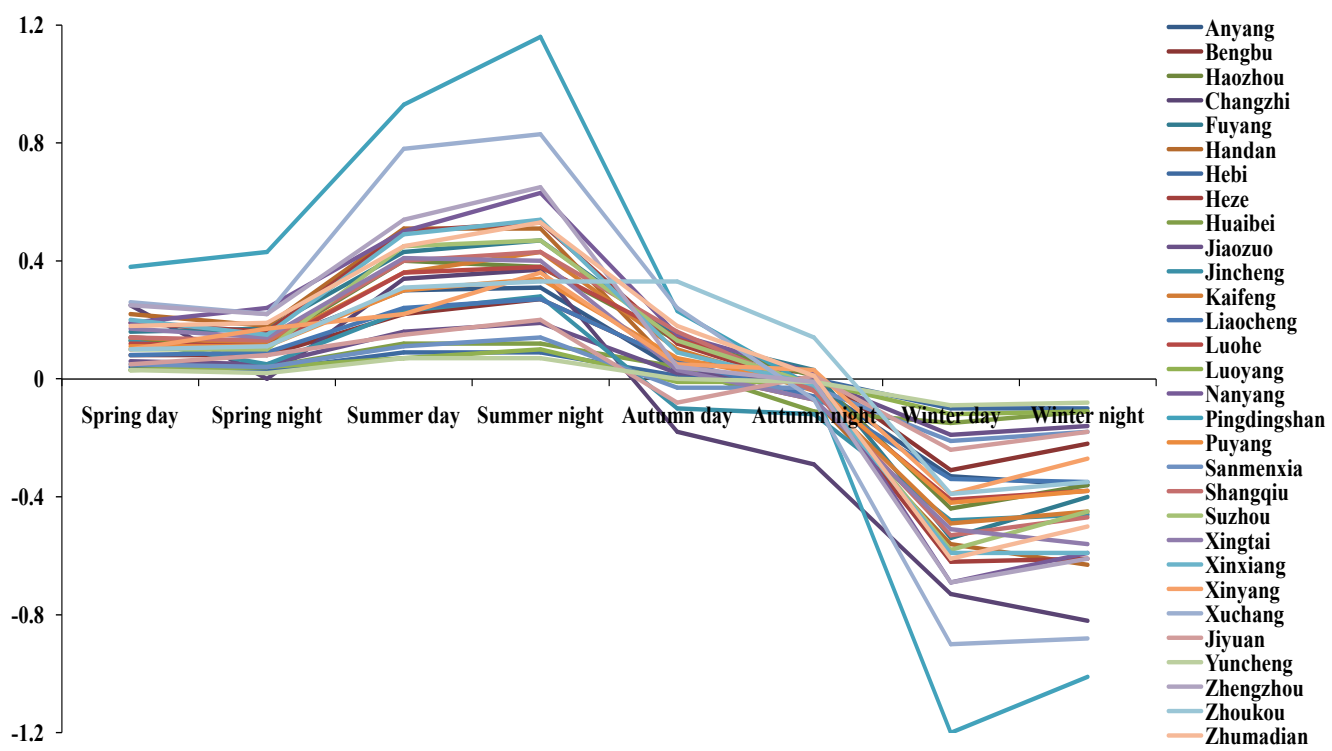

Fig. 6: Seasonal CI values of each city to the thermal environment of Zhongyuan urban agglomeration in 2018. 
Table 3: Seasonal CI values of each city to the thermal environment of Zhongyuan urban agglomeration in 2018.

\begin{tabular}{|c|c|c|c|c|c|c|c|c|}
\hline \multirow[t]{2}{*}{ City } & \multicolumn{2}{|c|}{ Spring } & \multicolumn{2}{|c|}{ Summer } & \multicolumn{2}{|c|}{ Autumn } & \multicolumn{2}{|c|}{ Winter } \\
\hline & Day & Night & Day & Night & Day & Night & Day & Nigh \\
\hline Anyang & 0.14 & 0.12 & 0.30 & 0.31 & 0.03 & -0.02 & -0.33 & -0.36 \\
\hline Bengbu & 0.08 & 0.08 & 0.22 & 0.27 & 0.06 & 0.02 & -0.31 & -0.22 \\
\hline Haozhou & 0.13 & 0.12 & 0.40 & 0.38 & 0.13 & 0.01 & -0.44 & -0.36 \\
\hline Changzhi & 0.25 & 0.00 & 0.34 & 0.37 & -0.18 & -0.29 & -0.73 & -0.82 \\
\hline Fuyang & 0.16 & 0.17 & 0.43 & 0.47 & 0.14 & 0.03 & -0.54 & -0.40 \\
\hline Handan & 0.22 & 0.18 & 0.51 & 0.51 & 0.03 & -0.07 & -0.56 & -0.63 \\
\hline Hebi & 0.04 & 0.03 & 0.09 & 0.09 & 0.01 & 0.00 & -0.10 & -0.10 \\
\hline Heze & 0.19 & 0.16 & 0.50 & 0.53 & 0.12 & -0.03 & -0.62 & -0.61 \\
\hline Huaibei & 0.03 & 0.04 & 0.12 & 0.12 & 0.04 & -0.11 & -0.15 & -0.11 \\
\hline Jiaozuo & 0.06 & 0.05 & 0.16 & 0.19 & 0.02 & 0.00 & -0.19 & -0.16 \\
\hline Jincheng & 0.13 & 0.05 & 0.23 & 0.28 & -0.10 & -0.12 & -0.48 & -0.46 \\
\hline Kaifeng & 0.14 & 0.12 & 0.36 & 0.43 & 0.10 & -0.04 & -0.49 & -0.45 \\
\hline Liaocheng & 0.08 & 0.09 & 0.24 & 0.27 & 0.06 & -0.06 & -0.34 & -0.35 \\
\hline Luohe & 0.12 & 0.11 & 0.36 & 0.38 & 0.14 & -0.03 & -0.41 & -0.38 \\
\hline Luoyang & 0.03 & 0.04 & 0.07 & 0.10 & -0.01 & -0.01 & -0.12 & -0.11 \\
\hline Nanyang & 0.19 & 0.24 & 0.50 & 0.63 & 0.15 & 0.02 & -0.69 & -0.59 \\
\hline Pingdingshan & 0.38 & 0.43 & 0.93 & 1.16 & 0.23 & -0.03 & -1.20 & -1.01 \\
\hline Puyang & 0.11 & 0.11 & 0.30 & 0.34 & 0.07 & -0.02 & -0.42 & -0.38 \\
\hline Sanmenxia & 0.05 & 0.04 & 0.11 & 0.14 & -0.03 & -0.03 & -0.21 & -0.18 \\
\hline Shangqiu & 0.14 & 0.13 & 0.40 & 0.43 & 0.16 & -0.04 & -0.53 & -0.47 \\
\hline Suzhou & 0.10 & 0.10 & 0.45 & 0.47 & 0.13 & -0.02 & -0.58 & -0.45 \\
\hline Xingtai & 0.17 & 0.14 & 0.41 & 0.40 & 0.03 & -0.07 & -0.51 & -0.56 \\
\hline Xinxiang & 0.20 & 0.15 & 0.49 & 0.54 & 0.09 & -0.02 & -0.59 & -0.59 \\
\hline Xinyang & 0.10 & 0.17 & 0.22 & 0.36 & 0.05 & 0.03 & -0.39 & -0.27 \\
\hline Xuchang & 0.26 & 0.22 & 0.78 & 0.83 & 0.24 & -0.07 & -0.90 & -0.88 \\
\hline Jiyuan & 0.05 & 0.08 & 0.15 & 0.20 & -0.08 & 0.01 & -0.24 & -0.18 \\
\hline Yuncheng & 0.03 & 0.02 & 0.07 & 0.07 & 0.00 & -0.01 & -0.09 & -0.08 \\
\hline Zhengzhou & 0.25 & 0.22 & 0.54 & 0.65 & 0.04 & -0.01 & -0.69 & -0.61 \\
\hline Zhoukou & 0.10 & 0.11 & 0.31 & 0.33 & 0.33 & 0.14 & -0.39 & -0.35 \\
\hline Zhumadian & 0.18 & 0.19 & 0.45 & 0.53 & 0.18 & 0.01 & -0.61 & -0.50 \\
\hline
\end{tabular}

city was the most typical. The diurnal CI value to the thermal environment was 1.05 in summer and -1.10 in winter, which was smaller than those in spring (0.41) and autumn (0.10). The absolute CI values of Yuncheng city, Luoyang city, Huaibei city, and Hebi city were generally low, and the seasonal differences in the CI value were minor; among which, the diurnal average $\mathrm{CI}$ values of Yuncheng city in the four seasons all fluctuated around 0 , being $0.02,0.07,0.00$ and -0.08 in spring, summer, autumn, and winter, respectively. The difference between daytime $\mathrm{CI}$ and nighttime $\mathrm{CI}$ to the thermal environment was not large. In general, the abovementioned cities exerted a warming effect on the thermal environment 
in the study area in spring and summer and a cooling effect in autumn and winter.

\section{CONCLUSIONS}

This study aimed to clarify the influence laws of land utilization type differences and changes in the regional thermal environment in different seasons and under different daytime and nighttime conditions. Zhongyuan urban agglomeration was taken as the study area, and the MODIS temperature product and land utilization data were utilized to analyze the influence laws of different cities and different land utilization types on the regional thermal environment by using the contribution index from the angles of interannual differences and seasonal differences. The following conclusions could be drawn:

(1) The farmland and forest land appeared to influence the thermal environment of Zhongyuan urban agglomeration most significantly, which was mainly manifested by two aspects: influenced area and influence intensity. The farmland accounted for the largest proportion in the total study area, with the CI value increasing from 0.31 in 2010 to 0.43 in 2018, and the warming effect on the regional thermal environment was apparently strengthened. The CI value of forest land was transformed from -0.31 in 2010 to -0.41 in 2018, and its cooling effect on the regional thermal environment was also enhanced.

(2) The contribution of farmland to the regional thermal environment showed significant daytime and nighttime differences, where the warming effect in the daytime was more obvious than that in the nighttime. The seasonal CI values of forest land were basically negative, and the cooling effect was the most remarkable in summer and autumn. In different seasons and under different daytime and nighttime conditions, the construction land showed a strong warming effect on the thermal environment of the urban agglomeration.

(3) In different years and different daytime and nighttime conditions, the CI values of Changzhi city and Jincheng city to the thermal environment were negative, exerting a certain cooling effect on Zhongyuan urban agglomeration. The CI values of Handan city, Liaocheng city, and Xingtai city were positive in the daytime and negative in the nighttime. The cooling and warming roles of the urban thermal environment were transited under different daytime and nighttime conditions from the warming role into the cooling role.

(4) The contributions of different cities to the thermal environment in Zhongyuan urban agglomeration presented seasonal differences. The CI value was greater than 0 in spring and summer, and it could be either positive or negative in autumn and winter. Meanwhile, the seasonal differences in the contribution to the thermal environment were the most apparent in summer and winter.

Besides being affected by human factors and natural factors, the CI index to the thermal environment is also related to the landform, anthropogenic emissions, etc. Hence, some uncertain factors still exist in research on the thermal environment of urban agglomeration by using the CI index. Furthermore, the MODIS temperature product with the precision of $1 \mathrm{~K}$ used in this study can meet the research needs to some extent. However, the thermal environment of urban agglomeration with higher precision data remains to be further investigated.

\section{ACKNOWLEDGEMENTS}

This study was supported by Key Scientific Research Projects of Colleges and Universities in Henan Province (21A420003), Doctoral Fund of Henan Institute of Engineering (D2016005) and The Ninth Batch of Provincial Key Discipline (Geodesy and Surveying Engineering) Project in Henan Province (JiaoGao [2018] No.119). The authors are grateful to the student of Henan Institute of Engineering for their support during data processing.

\section{REFERENCES}

Carlson, T.N. and Arthur, S.T. 2000. The impact of land use-land cover changes due to urbanization on surface microclimate and hydrology: a satellite perspective. Global and Planetary Change, 25(1-2):49-65.

Chi, W.F., Shi, W.J. and Kuang, W.H. 2015. Spatio-temporal characteristics of intra-urban land cover in the cities of China and USA from 1978 to 2010. Journal of Geographical Sciences, 25(1): 3-18.

Dai, X.Y., Zhang, L.Q. and Guo, Z.Y. et al. 2009. Mechanism of formation of urban heat island effect and its spatial pattern in Shanghai. Acta Ecologica Sinica, 29(7): 3995-4004.

Han, D.R., Xu, X.L. and Li, J. et al. 2017. Study on the security pattern of the heat environment and the influence of land use change in the Yangtze River Delta urban agglomeration. Journal of Geo-information Science, 19(1): 39-49.

Jia, J.T. 2014. Estimation of evapotranspiration in mountainous city- A case study in Chongqing. Chongqing: Master Degree Thesis of Chongqing Normal University, China.

Liu, J.Y., Liu, M.L., Zhuang, D.F. et al. 2003. Study on spatial pattern of land-use change in China during 1995-2000. Science in China (Series D:Earth Sciences), 46(4): 373-384+420-422.

Liu, J.Y., Kuang, W.H., Zhang, Z.X. et al. 2014. Spatiotemporal characteristics, patterns and causes of land use changes in China since the late 1980s. Journal of Geographical Sciences, 24(2): 195-210.

Memon, R.A., Leung, D.Y.C. and Liu, C. 2008. A review on the generation, determination and mitigation of Urban Heat Island. Journal of Environmental Sciences, 20(1): 120-128.

Meng, W.G., Zhang, Y.X., Li, J.N. et al. 2010. Application of WRF/ UCM in the simulation of a heat wave event and urban heat island around Guangzhou city. Journal of Tropical Meteorology, 26(3): 273-282. 
Oke, T.R. and Cleugh, H.A. 1987. Urban heat-storage derived as energy-balance residuals. Boundary-Layer Meteorology, 39(3): 233-245.

Peng, S.S., Piao, S.L., Zeng, Z.Z. et al. 2014. Afforestation in China cools local land surface temperature. Proceedings of the National Academy of Sciences of the United States of America, 111(8): 2915-2919.

Qiao, Z., Sun, Z.Y., Sun, X.H. et al. 2019. Prediction and analysis of urban thermal environment risk and its spatio-temporal pattern. Acta Ecologica Sinica, 39(2): 649-659.

Qiao, Z. and Tian, G.J. 2014. Spatiotemporal diversity and regionalization of the urban thermal environment in Beijing. Journal of Remote Sensing, 18(3): 715-734.

Qiao, Z., Tian, G.J. and Xiao, L. 2013. Diurnal and seasonal impacts of urbanization on the urban thermal environment: A case study of Beijing using MODIS data. ISPRS Journal of Photogrammetry \& Remote Sensing, 85: 93-101.

Rigo, G., Parlow, E. and Oesch, D. 2006. Validation of satellite observed thermal emission with in-situ measurements over an urban surface. Remote Sensing of Environment, 104(2): 201-210.

Streutker, D.R. 2002. A remote sensing study of the urban heat island of Houston, Texas. International Journal of Remote Sensing, 23(13): 2595-2608.

Sun, Z.Y., Sun, X.H., Xu, X.L. et al. 2018. Study on the contribution of land use heterogeneity and change to regional thermal environment: a case study of Beijing-Tianjin-Hebei urban agglomeration. Ecology and Environmental Sciences, 27(7): 1313-1322.

Tang, Z., Zheng, H.F., Ren, Z.B. et al. 2017. Spatial and temporal changes to urban surface thermal landscape patterns: a case study of Changchun city. Acta Ecologica Sinica, 37(10): 3264-3273.
Wang, M., Meng, H., Bai, Y. et al. 2013. Relationships between landscapes spatial pattern and land surface temperature in Shanghai. Ecology and Environmental Sciences, 22(2): 343-350.

Wan, Z., Zhang, Y., Zhang, Q. et al. 2004. Quality assessment and validation of the MODIS global land surface temperature. International Journal of Remote Sensing, 25(1): 261-274.

Xie, Z.Y., Huang, T., Li, Y.J. et al. 2019. Study on the relationship between spatial-temporal evolution of land use and of urban heat environment in Nanchang. Environmental Science \& Technology, 42(S1): 241-248.

Xu, S.L. 2009. An approach to analyzing the intensity of the daytime surface urban heat island effect at a local scale. Environmental Monitoring and Assessment, 151(1): 289-300.

Yue, W.Z., Xu, L.H. and Xu, J.H. 2010. Thermal environment change and its socioeconomic drivers in Shanghai City during the 1990s. Acta Ecologica Sinica, 30(1): 155-164.

Zhang, Y., Bao, W.J., Qi, Y. et al. 2012. Study on seasonal variations of the urban heat island and its interannual changes in a typical Chinese megacity. Chinese Journal of Geophysics, 55(4): 1121-1128.

Zhou, R.W., Jiang, W.M. and He, X.F. 2008. Numerical simulation of the impacts of the thermal effects of urban canopy structure on the formation and the intensity of the urban heat island. Chinese Journal of Geophysics, 51(3): 715-726.

Zhou, W.Q., Qian, Y.G., Li, X.M. et al. 2014. Relationships between land cover and the surface urban heat island: seasonal variability and effects of spatial and thematic resolution of land cover data on predicting land surface temperatures. Landscape Ecology, 29(1): 153-167. 